\title{
REFLEXIONES EN TORNO A LA SOSTENIBILIDAD DE LA DEHESA
}

\author{
Pérez Díaz, A. \\ Departamento de Geografía y Ordenación del Territorio. \\ Facultad de Filosofía y Letras. Universidad de Extremadura \\ Avda. de la Universidad, s/n. Campus Universitario. 10071 Cáceres \\ E-mail: aperez@unex.es
}

\begin{abstract}
Resumen: En el último cuarto de siglo la dehesa española ha despertado un interés científico que sólo encuentra parangón y justificación en la creciente preocupación de la opinión pública por la conservación y restauración del medio ambiente. En poco tiempo, la dehesa ha pasado de ser el paradigma del latifundismo en su más peyorativa concepción, a convertirse en un modelo incuestionable de desarrollo sostenible. Sin negar a priori esta nueva concepción, este artículo trata de ofrecer las claves para una reflexión sobre la sostenibilidad pasada, presente y futura de la dehesa. Y pretende hacerlo desde una perspectiva geográfica, integradora, alejada de modas pasajeras y opiniones estereotipadas.
\end{abstract}

Palabras clave: Dehesa, economia, sostenibilidad, agrosistemas.

\begin{abstract}
In the last century room the Spanish dehesa have wakened up a scientific interest that he only finds paragon and justification in the growing concern of the public opinion for the conservation and restoration of the environment. In little time, the meadow has passed of being the paradigm of the "latifundismo" in its most pejorative conception, to become an unquestionable model of sustainable development. Without denying this new conception a priori, this article tries to offer the keys for a reflection on the last sostenibilidad, present and future of the meadow. And he seeks to make it from a geographical, integrative perspective, far from fleeting fashions and stereotyped opinions.
\end{abstract}

Key words: Dehesa, economy, sustainability, land-use systems.

\footnotetext{
* Recibido: 24-10-05. Aceptado: 18-1-06.
} 


\section{Introducción}

Escribir sobre la dehesa con la pretensión de arrojar nueva luz sobre este interesante sistema de explotación agraria no constituye, ciertamente, una tarea fácil. En las últimas décadas se ha escrito y se ha hablado más de la dehesa que en toda su historia. No se ha circunscrito este atractivo a un campo científico concreto. Por el contrario, se ha producido una confluencia de intereses científicos en el que no han faltado biólogos, ecólogos, ingenieros, economistas, sociólogos, geógrafos, antropólogos y, en fin, una pléyade de profesionales fascinados por el pasado, el presente y el futuro de estos espacios que tan genuina y tan generosamente están representados en buena parte del Oeste peninsular y, de modo especial, en Extremadura.

Esta confluencia de intereses científicos es en gran medida la responsable de que el concepto de dehesa se haya venido enriqueciendo hasta el punto de que su definición resulte cada vez más compleja y difícil de precisar. Obviamente, cada profesional se fija y se centra en aquello que satisface en mayor medida su curiosidad científica: unos destacan su origen y evolución histórica; otros se sienten atraídos por su riqueza geobotánica; son muchos los que se interesan por sus potencialidades agrarias y no son pocos, en fin, los que significan su idoneidad para la práctica del turismo rural y el despliegue de múltiples actividades vinculadas al desarrollo sostenible de estos espacios.

Para dar cabida a tan variadas percepciones y lograr un ajuste mejor a los parámetros del desarrollo sostenible, probablemente sea conveniente hablar de paisajes adehesados más que de dehesas propiamente dichas, aunque ambos conceptos se hallen indisolublemente unidos. $Y$ es que hablar de paisajes adehesados es hacerlo de unos territorios aglutinados por una similitud fisonómica, económica, social y cultural que les confiere cohesión y continuidad más allá y por encima de los límites administrativos, sean estos regionales o, como en el caso del vecino Portugal, internacionales. Es cierto, no obstante, que el eje vertebrador de estos espacios lo constituye la dehesa, entendida ésta como sistema productivo que en su andadura histórica ha tratado de rentabilizar unos recursos naturales variables en el espacio, a través de una actividad agropecuaria que se ha visto abocada a sensibles transformaciones a lo largo del tiempo, y con una capacidad y unos criterios financieros claramente variables de unos casos a otros (Rubio, 1999).

Por otra parte, resulta necesario un análisis de estos espacios desde una perspectiva geográfica, integradora, que proporcione elementos para enjuiciar la sostenibilidad pasada, presente y futura de la dehesa por encima de opiniones estereotipadas y modas que, como tales, sólo son pasajeras. 


\section{Condicionantes físicos}

En lo que respecta a las condiciones ambientales en las que se desenvuelve la actividad agraria dominante en los paisajes adehesados, debe significarse su sometimiento a los condicionamientos topográficos, al rigor del clima, a la mediocridad de los suelos y, en función de tales variables, a la debilidad y aleatoriedad de la producción vegetal y la escasez de agua.

Ciertamente, las dificultades topográficas no tienen porqué ser determinantes en el funcionamiento de la dehesa o, al menos, no llegan a ejercer una acción tan concluyente como en los espacios de montaña. Es cierto que habitualmente limitan las actividades agrícolas, obstaculizan el trabajo de la maquinaria y obligan a una selección del ganado acorde con tales impedimentos. Sin embargo, la verdadera importancia del relieve se significa en la presencia de subsistemas dentro de la dehesa y en la articulación y la transferencia de nutrientes que se produce entre ellos.

De forma natural, el agua, los minerales y la materia orgánica emigran desde las zonas altas a las bajas que, en consecuencia, disponen de suelos más profundos, más fértiles y con mayor disponibilidad de agua y producen pastos más jugosos. Los llanos y las laderas más suaves, donde el riesgo de erosión es más débil, han constituido tradicionalmente los sectores destinados a la siembra de cereales y leguminosas; el arbolado alcanza mayores densidades en los terrenos donde la pendiente imposibilita el cultivo, y las cumbres y cabezos constituyen las manchas donde ramonean las cabras y donde se oculta esa fauna cinegética cuya gestión sigue constituyendo la asignatura pendiente de la dehesa.

El ganado, por su parte, actúa como un "vector de fertilidad" contrario a la gravedad, ya que, aunque alternando temporalmente sus preferencias, transita entre las zonas bajas, donde se alimenta, y las altas, donde establece sus querencias. Mediante sus deyecciones, pues, transfiere energía de unos emplazamientos a otros (Fernández, 1998).

El clima, en principio, no parece ofrecer un cuadro excesivamente desfavorable para el desarrollo de la actividad ganadera. El volumen medio de las precipitaciones, con valores que oscilan entre los $500 \mathrm{~mm}$ de los terrenos más bajos e interiores y los más de $800 \mathrm{~mm}$ de los sectores serranos, es suficiente para cubrir las necesidades medias del arbolado y los pastos. Pese a su carácter extremo, tampoco las temperaturas imponen duras exigencias de manejo para unas especies ganaderas cuyo elevado grado de rusticidad les permite soportar los rigores de inviernos y veranos. Bien es cierto, no obstante, que tanto las bajas temperaturas invernales como los altos 
registros del estío provocan una escasez de alimentos que exige una suplementación del ganado bien basada en granos, rastrojos y ramones, como ocurriera antaño, bien en henos y piensos, como suele ser habitual ahora.

Con todo, no son éstas las limitaciones más señeras que impone el clima, ya que los ganaderos las conocen y han encontrado el modo de afrontarlas. El verdadero obstáculo radica en la irregularidad anual e interanual de las precipitaciones. En su ritmo anual éstas llegan con el otoño, aumentan gradualmente hasta alcanzar su máximo en los meses centrales del invierno e inician un progresivo descenso que tras la primavera desemboca en los mínimos absolutos de julio y agosto. Pero este régimen medio enmascara la existencia de acusadas fluctuaciones. A años excepcionalmente lluviosos pueden sucederles otros extraordinariamente secos. Algunos otoños no hacen más que prolongar la aridez estival, que también suele caracterizar en ocasiones a gran parte de la estación primaveral. Poco puede hacer pues, el ganadero, ante tales imprevistos meteorológicos. De ahí que sean éstos los principales responsables de algunas de las situaciones de riesgo a que se ve abocada la sostenibilidad de la dehesa. Y no sólo por la escasez de hierba y pasto, que agudizan los problemas de erosión y minan la economía de la empresa agraria, sino también por los graves inconvenientes que plantea la falta de agua.

El suelo, otro factor de innegable significación en la configuración de los paisajes de dehesa, también impone graves limitaciones productivas a este tipo de agrosistemas. Formado generalmente sobre pizarras y granitos, el soporte edáfico de la dehesa suele aparecer caracterizado por su superficialidad y erosionabilidad, escaso contenido en materia orgánica, débil capacidad para retener la humedad, excesiva pedregosidad y bajo $\mathrm{pH}$... circunstancias todas explicativas de la vocación pecuaria de estos terrenos y de la importancia del barbecho y la amplitud de las rotaciones en la hoja de labor.

Por último, la vegetación constituye un factor natural de influencia decisiva en la configuración y el equilibrio ecológico de la dehesa. En sus diferentes estratos, actúa reduciendo la erosión por salpicadura y escorrentía; protege al suelo de una insolación excesiva, previniéndole de una pérdida rápida de humedad; atenúa la radiación nocturna y el consiguiente efecto de las heladas; favorece la filtración, dota al suelo de materia orgánica, fósforo y potasio... al margen de proporcionar los recursos pastables necesarios para la alimentación del ganado (Zavala, 2004).

Relieve, clima, suelos y vegetación son, pues, factores decisivos en la conformación de los paisajes adehesados, un marco natural de extremada fragilidad en el que la intervención del hombre puede resultar tan peligrosa como necesaria para garan- 
tizar su sostenibilidad ambiental: la sobrecarga ganadera o el laboreo excesivo pueden conducir a un empobrecimiento del pastizal o a la erosión y agotamiento del suelo; la debilidad de la carga o el abandono del cultivo provocarían, empero, una invasión del matorral. Las podas abusivas y el aclareo indiscriminado conducen a la desaparición del arbolado, con la consiguiente merma de recursos económicos y medioambientales que ello representa; no obstante, un abandono o espaciamiento excesivo en la realización de tales labores deriva en un aumento de la producción de leña en detrimento de la bellota o el corcho, en un exceso de árboles y en una invasión del matorral que merman la capacidad productiva del propio arbolado y de los pastos.

Como Sísifo, el empresariado de la dehesa parece obligado a sostener una carga que rodará ladera abajo tanto si se excede como si se descuida en su esfuerzo. Pese a todo, ha logrado compatibilizar el uso y la conservación de estos recursos naturales durante siglos, y lo ha hecho practicando un sistema multiproductivo basado en el aprovechamiento mixto del monte, el pastizal y el terreno de labor. En esencia, esta complementa-riedad en el uso de suelo y vuelo ha mostrado signos de estabilidad a lo largo del tiempo. Sin embargo, con éste han cambiado los condicionamientos socio-económicos, técnicos y culturales. $Y$, con ellos, lo han hecho también los hombres, sus necesidades, sus inquietudes y sus métodos de trabajo. No es difícil comprobar, al respecto, que la dehesa ha pasado de ser considerada como uno de los reductos del latifundismo en su más peyorativa concepción, a uno de los sistemas paradigmáticos en lo que a relación cordial entre hombre y naturaleza, y entre economía y ecología se refiere (Pérez, 1994).

Ese cambio de apreciación se encuentra estrechamente vinculado a las espectaculares transformaciones que ha experimentado la concepción global de la agricultura en los últimos años. El modelo productivista adoptado en nuestro país a partir de los años sesenta parece obligado a dejar paso a nuevos esquemas y planteamientos productivos tras las sucesivas reformas de la Política Agraria Comunitaria y, en relación con ellas, las crecientes presiones de la Organización Mundial del Comercio. No cabe duda de que todo esto ha abierto nuevas perspectivas para el futuro de la dehesa. Mas, para poder valorar tales expectativas, no puede soslayarse una mirada atrás, una visión retrospectiva que permita conocer qué factores han propiciado la evolución de la dehesa y qué riesgos han debido asumirse en tal proceso evolutivo. 


\section{Influencia del contexto socio-económico}

Obviamente, si bien el marco natural apenas ha experimentado variaciones significativas en los últimos siglos, el contexto socio-económico no ha mostrado el mismo grado de estabilidad. Y, precisamente, han sido cambios de esta índole los que han propiciado la existencia de tres fases en las que la pretendida sostenibilidad de la dehesa ha debido desenvolverse en condiciones distintas y con características diferentes. La primera de ellas debe hacerse coincidir con el largo período en que se consolidó el esquema productivo de la dehesa tradicional que, amparado en la abundancia y bajo precio de la mano de obra, generó el marco adecuado para la sostenibilidad ambiental, social y económica de la dehesa. La segunda fase se identifica con la intensificación productiva que se logró entre los años sesenta y mediados de los ochenta, y sirve de referencia para evaluar las consecuencias que se derivaron de la crisis socioeconómica que sufrieron estos espacios como consecuencia, ante todo, del fuerte éxodo poblacional al que se vieron sometidos. Y, finalmente, la dehesa actual, el sistema de explotación que se conforma tras la incorporación a la antigua CEE y los continuos reajustes que exige la aplicación de la PAC, y que permite sentar unas bases de reflexión sobre el futuro de estas unidades de producción y el del territorio en el que se enmarcan.

\subsection{Las claves de la sostenibilidad en la dehesa tradicional}

Para hacer frente a problemas como la relativa escasez e irregularidad estacional de la producción herbácea, el agotamiento estival de los abrevaderos naturales, la variabilidad de la cosecha de bellotas o el bajo rendimiento de la hoja de labor, el sistema productivo de la dehesa tradicional se apoyaba en cuatro pilares fundamentales (Pérez, 1988). En primer lugar, en una selección de especies y razas ganaderas autóctonas acorde con la cantidad y calidad de los recursos pastables o, lo que es lo mismo, acorde con su grado de resistencia y su aptitud para transformar en carne los pastos, frutos, ramones y subproductos agrícolas propios de estos territorios. Destacaban, de este modo, la oveja merina, el cerdo ibérico y el vacuno retinto y avileño, por citar los ejemplos más representativos.

En segundo lugar, la dehesa tradicional se caracterizó por el mantenimiento de una carga ganadera lo suficientemente débil como para poder asumir los riesgos inherentes a la irregularidad del clima. Además, debido a las características fisiológicas de las especies y razas autóctonas predominantes en la cabaña y, concretamente, en función de su escasa precocidad y de su bajo índice de conversión, la dehesa tradicio- 
nal se caracterizó por la amplitud de los ciclos productivos que era necesario cubrir para obtener un animal productivo o con peso adecuado para el sacrificio.

Y finalmente, para hacer frente a tales condicionamientos productivos, la dehesa necesitaba el concurso de una mano de obra notoriamente cuantiosa. Para lograr la rentabilidad de sus producciones era preciso disponer de reservas alimenticias obtenidas en la hoja de labor, y era imprescindible cuidar del arbolado, recoger y almacenar bellotas, contener manualmente la invasión del matorral, manejar al ganado y otra larga serie de labores de las que no deben excluirse las relacionadas con la gestión propia de cualquier actividad económica. En la dehesa encontraban empleo, fijo o eventual, guardas, manijeros, gañanes, porqueros, pastores, cortadores, sacadores de corcho, apañadores de bellota, piconeros, yunteros y aparceros que no sólo garantizaban el funcionamiento de las grandes explotaciones sino que además, debido a la baja cuantía de sus salarios, avalaban su autonomía económica y la obtención de sus plusvalías (Acosta, 2002). Podría asegurarse, en este sentido, que esta mano de obra abundante, barata y experta en las más diversas labores culturales, constituía una de las claves de sostenibilidad de la dehesa tradicional.

Sin lugar a dudas, la adaptación funcional de la dehesa a los condicionamientos ambientales no hubiera sido posible sin la existencia de una mano de obra abundante y barata, sin el atraso tecnológico y la baja capitalización del campo, sin la secular persistencia de una demanda perfectamente adaptada a la estacionalidad y composición de la oferta, sin el mantenimiento de unos niveles de renta que apenas se vieron alterados durante décadas, sin un contexto económico y político que imponía la resignación y el conformismo como normas de conducta social o sin un horizonte humano huérfano de esperanzas. De forma concatenada, todas estas circunstancias garantizaron durante siglos la gestión racional de un medio natural cicatero y frágil. Un medio que, pese a sus limitaciones, daba soporte a una actividad económica que resistía la creciente presión de una población que alcanzó el mayor dinamismo vegetativo de su historia en el ecuador de la pasada centuria. Cierto es que, poco tiempo después, todos estos presupuestos se vieron sustancialmente alterados. Se precipitaba así la crisis de la dehesa tradicional y la de todo el territorio que secularmente se había vertebrado en torno a este tipo de explotaciones. A partir de esos momentos, se produciría un desencuentro creciente entre los objetivos económicos, la demanda social y las exigencias ambientales del desarrollo sostenible.

\subsection{La quiebra del sistema}

La emigración de gran parte de la mano de obra agraria, la subida de los salarios, el incremento y modificación de la demanda que se derivó del aumento de la renta 
per capita, la necesidad de abastecer de manera continua los mercados urbanos, el derrumbamiento de los precios de la lana, principal producción del ganado ovino y motivo de merecida fama que alcanzó la oveja merina en el pasado, la aparición de la Peste Porcina Africana que afectó, por tanto, a la segunda especie más numerosa de la cabaña ganadera y llevó a la ruina a no pocas explotaciones ganaderas y, en fin, los nuevos planteamientos de la política agraria, obligaron a los empresarios a revisar sus esquemas productivos.

La extensividad, la obtención de cultivos y productos animales de marcado carácter tradicional, las bajas cargas ganaderas y el elevado consumo de trabajo humano que hasta entonces habían caracterizado $y$, sobre todo, garantizado la viabilidad económica, social y medioam-biental de la dehesa, se convirtieron a partir de los sesenta en un pesado lastre para este tipo de explotaciones. El equilibrio preexistente entre economía, población y aprovechamiento de los recursos ambientales sucumbió ante el obligado afianzamiento de unos planteamientos marcadamente rentabilistas. No en vano, los esfuerzos del empresariado de la dehesa debieron encaminarse desde entonces hacia la consecución de tres objetivos prioritarios: ahorrar mano de obra, acortar los ciclos de producción animal y adaptar sus producciones a las exigencias de una demanda sustancial-mente distinta a la preexistente. Paradójicamente, los medios arbitrados para conseguirlos iban a cercenar las posibilidades de desarrollo económico de los espacios adehesados y removerían los pilares de la sostenibilidad de la dehesa tradicional.

La imperiosa necesidad de reducir los costes salariales llevó al empresariado a reducir, espaciar o, las más de las veces, suprimir la hoja de cultivo. El abandono del aprovechamiento agrícola, perfectamente integrado en el complejo engranaje que articulaba el funcionamiento de la dehesa tradicional, no sólo tuvo unas consecuencias económicas perfectamente constatables en la pérdida de autonomía financiera de la empresa agraria, sino también ambientales y sociales. En el primer caso, la ausencia del arado no tardó en facilitar el apelmazamiento de los suelos, la invasión del matorral y el embastecimiento de los pastos. En el segundo, el desempleo forzado de jornaleros y aparceros, reavivó las llamas de una corriente emigratoria que dejó a los pueblos huérfanos de jóvenes y a los campos sembrados de soledad (Pérez y Barrientos, 2005).

Pese a todo, la falta de trabajo ha continuado actuando como un verdadero cáncer para el desarrollo de los espacios adehesados. Por eso, cuando la emigración dejó de ser la única alternativa a la ruptura de la relación simbiótica que la dehesa había mantenido con los pobladores de su territorio, hubieron de implementarse políticas asistenciales que aún hoy se mantienen vigentes. Tal fue el caso de la implantación 
del Empleo Comunitario en 1972, de su sustitución en 1984 por el Plan de Empleo Rural (PER) y la de éste, en 1996, por el Acuerdo para el empleo y la Protección social Agraria (AEPSA), modalidades éstas últimas que sólo fueron de aplicación en Extremadura y Andalucía.

En algunas ocasiones, la crisis ganadera hizo que el empresariado apostara por una cerealicultura mecanizada que también repercutió negativamente en la generación de empleo. En estos casos, además, la necesidad de facilitar el trabajo de la maquinaria, la crisis de las montaneras y la escasa demanda de leña y carbón, fueron suficientes para desencadenar arranques y aclareos de encinas de todo punto injustificables: la cifra de 134.000 hectáreas de encinar arrancado en Badajoz entre 1962 y 1974 que señalan algunos estudios, o las de 20.000 hectáreas de encinar descuajado anualmente que señalan otros autores, son de sobra elocuentes para valorar lo que dichas talas han debido suponer en el agotamiento, erosión y degradación de unos suelos de clara vocación pecuaria (Elena y Borrallo, 1989). En no pocos casos, ello ha representado la destrucción de la cobertura vegetal con el consiguiente aumento de la escorrentía superficial, la destrucción de la flora y la fauna originales, la erosión del suelo y, a la postre, la conversión de estos terrenos en eriales y baldíos.

Tampoco el acortamiento de los ciclos productivos y la acomodación de la oferta a la demanda estuvieron exentos de efectos negativos sobre la sostenibilidad de la dehesa. La consecución de estos dos objetivos, condición sine qua non para garantizar la viabilidad económica de estas explotaciones en el nuevo contexto socio-económico, debió pasar por una mejora genética y alimenticia de la cabaña ganadera (Pérez, 1993). La primera de esas vías exigió la introducción de animales de razas extranjeras bien para su explotación en pureza, bien, las más de las veces, para la práctica de cruzamientos industriales con reproductoras de razas locales. Fue así como se consiguió aumentar la prolificidad y la precocidad de la cabaña y se obtuvieron canales más adaptadas al gusto de los consumidores, al tiempo que se conservaba la rusticidad del ganado autóctono.

Por su parte, la mejora alimenticia se basó en la utilización creciente de piensos de origen industrial que, además de reemplazar a los cereales y leguminosas que antaño se obtenían en la hoja de labor, debía satisfacer las mayores exigencias nutritivas que comportaba la especialización productiva de la nueva cabaña. Los costes en alimentación representan desde entonces uno de los capítulos más importantes en el conjunto de gastos de la empresa agraria. Una empresa que, en definitiva, se ha visto obligada a sacrificar su independencia genética y alimenticia en aras de la modernización. 
En conclusión, pues, el proceso de modernización pecuaria que se inició en los años sesenta supuso un drástico cambio en la relación entre el hombre y el medio natural. Mientras que hasta entonces fueron las condiciones físicas las que definieron una configuración muy concreta del modelo ganadero, a partir de estas fechas fueron las circunstancias de índole socioeconómica las que condicionaron de manera definitiva el funcionamiento de las unidades de producción. Para afrontar el aumento de los salarios y las nuevas exigencias de la demanda había que romper con los moldes tradicionales de explotación y ello, qué duda cabe, ha tenido su reflejo más o menos inmediato y más o menos ostensible sobre el medio ambiente.

De este modo, ese proceso de modernización ha supuesto un aumento significativo de la carga ganadera, que ha pasado de los $65 \mathrm{Kg}$. de peso vivo/Ha. en 1962, a los $185 \mathrm{Kg}$./ha actuales (Escribano et al., 2002). Son frecuentes los casos de sobrecarga estacional y sobrepastoreo, con los consiguientes riesgos de degradación del estrato herbáceo, la destrucción de la estructura edáfica superficial y, en relación con ello, la erosión del suelo. No obstante, es preciso advertir que esta relación entre aumento de la carga ganadera y crosión del suelo no se produce de modo necesario, ya que depende más de la especie animal y del manejo del ganado que del peso vivo/Ha.

Además, al aumentar la carga ganadera se incrementa el aporte de estiércol al suelo, una consecuencia ésta que es positiva, en general, puesto que enriquece el contenido en materia orgánica del mismo, pero que si no se acompaña de un adecuado sistema de majadeo implica una contaminación de determinados sectores de la explotación, máxime cuando ahora esos residuos orgánicos contienen un grado variable de sustancias químicas utilizadas en la fabricación de piensos, correctores vitaminicos y productos zoosanitarios. Es fácil comprobar como habitualmente aparecen encinas secas o muy deterioradas en los sestiles o mosquiles donde se acumulan las deyecciones animales.

Por otro lado, la importación de animales de razas extranjeras llegó a poner en peligro de desaparición algunos de los recursos genéticos que garantizaban una perfecta adaptación medio-ambiental. Así ocurrió con el vacuno de la raza Blanca Cacereña y, aunque hoy pueda resultar inverosímil, con el porcino de la raza Ibérica: mientras que en 1955 las reproductoras de cerdo ibérico representaban el 36,6 por 100 del total de cerdas de vientre censadas en España, en 1982 su participación había quedado reducida a un 3,9 por 100 (Pérez, 1988)

De igual modo, algunos empresarios optaron por reconvertir parte de los terrenos de su explotación hacia un uso forestal, repoblando determinadas zonas con espe- 
cies alóctonas, fundamentalmente eucaliptos, con todas las consecuencias medioambientales que de ello se derivan: arranque y descuaje de la vegetación preexistente; preparación del suelo para acoger las nuevas especies forestales; alteración del régimen termohídrico del suelo, variación del pH, mezcla de horizontes, aumento de la erosión, eliminación de algunas especies faunísticas adaptadas a la vegetación preexistente, aumento de la turbidez del agua en las inmediaciones y, obviamente, un claro e intenso impacto paisajístico (Márquez, 1977. Alvarado, 1983).

A grandes rasgos, estos podrían ser algunos de los cambios más significativos en el proceso de configuración de la dehesa actual. Es cierto que detrás de ellos se ocultan un sinnúmero de detalles y matices, pero lo expuesto puede ser suficiente para valorar las consecuencias sociales medioambientales que se han derivado de algunas actuaciones humanas encaminadas exclusivamente a mantener el nivel de rentabilidad de las explotaciones, a no perder el tren de la modernización que se puso en marcha a lo largo de la década de los sesenta y, en fin, a afrontar los múltiples retos que han planteado los intensos cambios experimentados en el contexto socio-económico. Fue así, en definitiva, como se configuró la dehesa que, como el resto del sector agrario, se incorporó a la antigua CEE el 1 de enero de 1986.

\subsection{La PAC y sus efectos}

La adhesión comunitaria volvió a sembrar la inquietud y el desconcierto entre el empresariado de la dehesa. A mediados de los ochenta, y a pesar de los esfuerzos realizados en aras de la modernización, estas explotaciones se hallaban sumidas en una verdadera crisis de rentabilidad debida no sólo al encarecimiento de los principales insumos, sino también a la falta de control sobre los mercados y, en relación con ello, a la constante fluctuación de los precios del ganado. Estos territorios eran por entonces, y en gran medida lo siguen siendo aún, exportadores netos de terneros, corderos, cerdos y corcho, por señalar tan sólo algunas de las más genuinas producciones de la dehesa.

El mercado comunitario, por su parte, no parecía ofrecer muy buenas perspectivas para las producciones ganaderas. El vacuno de carne, que durante más de veinte años se había consolidado como la base de la modernización de la dehesa y como alternativa a la crisis de rentabilidad del ovino y porcino, no solamente iba a tener que enfrentarse a los problemas comerciales de un mercado excedentario, sino que iba a tener que competir con la mayor productividad del vacuno europeo. Por otro lado, la permanencia de la Peste Porcina Africana impedía la comercialización del 
cerdo ibérico y sus derivados, ensombreciendo de este modo el porvenir de una de las especies mejor adaptadas a los condicionamientos productivos de la dehesa. Sólo el subsector ovino, que por entonces era deficitario en Europa, parecía disponer de algunas ventajas en el nuevo mercado, aunque lo cierto es que, también en este caso, los inconvenientes a corregir eran innumerables (Pérez, 1986).

Pero lo cierto es que la incorporación a la CEE no sólo iba a significar un reto comercial, sino que a la postre ha supuesto una nueva actitud y una nueva concepción de la dehesa. La Política Agraria Común no sólo se ha convertido en el eje vertebrador de estas explotaciones extensivas, sino también, en buena medida, de todo el marco territorial en el que se insertan. Además de contribuir a mantener la renta de los productores, la aplicación de la PAC ha propiciado la formación y capacitación del empresariado, ha favorecido el desarrollo tecnológico del sector, ha servido para fomentar el asociacionismo entre los productores, ha incentivado la readaptación de las unidades de producción y ha reactivado la industrialización y comercialización de algunos productos ganaderos, con el consiguiente efecto estabilizador sobre sus correspondientes mercados (Pérez, 2003).

Uno de los sectores beneficiados con la adopción de la PAC ha sido el vacuno de carne ya que, en poco más de dieciocho años, se ha multiplicado por más de dos el número de vacas. Es cierto que parte de este incremento se debe a la mayor veracidad de los datos aportados por los ganaderos y al mayor control estadístico que se ejerce desde la Administración. La generosidad de las primas, sin embargo, ha desempeñado un papel esencial en el crecimiento censal de la especie. No en vano, los productores extremeños recibieron en 2003 algo más de 61,5 millones de euros en concepto de primas por vaca nodriza, lo que unido a otras primas destinadas al sector, arrojó un montante total superior a los 118,4 millones de euros (Díaz y Sánchez, 2004).

A la positiva evolución del vacuno de carne es necesario añadir el incremento, en más de un 48 por 100, del censo de reproductoras de ovino. Y, también en este caso, han sido las subvenciones el principal factor de dinamización del sector. Según datos del año 2003, las ayudas recibidas por el ovino y caprino se situaron en 93,2 millones de euros, es decir, casi el 41 por 100 de la producción final del subsector ovino (Díaz y Sánchez, 2004). Sin duda, estos datos indican que las explotaciones mantienen una dependencia excesiva respecto de las ayudas comunitarias, que resultan enormemente vulnerables ante cualquier reforma de la PAC en dicho sentido y que, por tanto, pese a que han transcurrido casi veinte años desde la adhesión, aún carecen de bases sólidas sobre las que cimentar su futuro. 
El ganado porcino sin embargo, aunque ajeno a este sistema de primas directas, ha logrado vencer el estancamiento censal que lo caracterizó en la primera mitad de los ochenta y se ha incrementado en más del doble entre los años 1986 y 2003 . La erradicación de la Peste Porcina Africana, la creación de nuevos mataderos y fábricas de embutidos, la apertura del mercado internacional a los derivados del cerdo ibérico y, cómo no, la consecución de la denominación de origen "Dehesa de Extremadura" son algunas de las razones que justifican este aumento y que han convertido al porcino en una de las especies de mayor importancia económica en la ganadería regional.

Según datos de 2003, el valor del porcino representó el 30,8 por 100 de la producción final animal de Extremadura. Es conveniente precisar, en este sentido, que el verdadero protagonista del relanzamiento experimentado por el sector después de no pocos períodos de crisis e incertidumbres, ha sido el cerdo ibérico, que contribuye en más del 90 por 100 al valor conjunto del sector. La superación de los añejos problemas sanitarios y la decidida apuesta por la obtención de productos de calidad ha permitido que la producción del cerdo ibérico alcance una facturación anual superior a los 85,34 millones de euros, sirva de soporte a 211 empresas de la región y emplee a más de 21.000 personas (Díaz y Sánchez, 2004). Se trata, ciertamente, de un avance rápido y espectacular. Con todo, algo más de la mitad de los cerdos producidos en Extremadura salen de la región con destino a otros mataderos nacionales y, ante la falta de clarificación del mercado, es creciente la competencia del ibérico obtenido mediante sistemas de producción intensivos, cuyos productos inundan los mercados a precios mucho más competitivos.

En conclusión, pues, debe admitirse que la adhesión comunitaria ha reportado sustanciosas ventajas a la ganadería y con ello ha contribuido decisivamente a reflotar la situación socio-económica del amplio marco territorial en el que se inserta la clehesa. Y ha sido este ambiente bonancible el que ha permitido replantear muchas de las situaciones indeseables que antaño amenazaron la integridad ambiental de la dehesa, erosionaron sobremanera la rentabilidad de la empresa agraria y reavivaron la corriente emigratoria de este vasto territorio peninsular. Han sido, una vez más, los vientos favorables a la economía los que han permitido corregir los desvaríos que se cometieron en la gestión ambiental y empresarial de la dehesa.

Ciertamente, no es difícil encontrar argumentos que justifiquen esta apreciación. De este modo, las ayudas comunitarias para la forestación de tierras agrarias, no sólo han permitido la repoblación y mejora forestal de cientos de miles de hectáreas, sino que también han generado cientos de miles de jornales en los medios rurales, con el consiguiente alivio del desempleo agrario, y han suscitado la creación de numerosas empresas dedicadas a la producción de planta forestal y la prestación de los múltiples servicios demandados por los beneficiarios de estas ayudas. 
En idéntico sentido se han conjugado las variables ambientales, sociales y económicas, tras el relanzamiento del mercado del cerdo ibérico. La erradicación de la Peste Porcina Africana, la creación de mercados específicos de calidad, la creciente demanda de jamones y embutidos y el aumento subsiguiente de sus precios, no sólo han despertado una pasión por la mejora de esta raza porcina autóctona, otrora condenada a la extinción, sino que también han reavivado el interés por la atención y cuidado del arbolado de quercíneas, han mejorado la renta de los ganaderos, han propiciado un sensible aumento del número de mataderos y fábricas de embutidos y, han contribuido, en fin, a mejorar el nivel de vida de la población y a equilibrar el balance migratorio. Todo parece indicar que la dehesa ha vuelto a convertirse en un modelo indubitable de desarrollo sostenible.

\section{Conclusión: Algunas claves para la sostenibilidad futura de la dehesa}

Ante la realidad descrita, no sería difícil colegir que el empresariado de la dehesa ha mostrado a lo largo de la última década mucha mayor coherencia de la que manifestó en los años sesenta y setenta. Ahora bien, desde una perspectiva estrictamente empresarial, probablemente no fuera tan sencillo llegar a la misma conclusión, ya que también entonces actuó en consonancia con las condiciones del mercado. Es obvio que el empresariado de la dehesa, como el de cualquier otra actividad económica, procura y debe procurar la rentabilidad de su negocio, pues de otro modo no sería un buen profesional. Tan sólo hay una particularidad, y es que en este caso debe ser consciente de que la economía de su explotación depende, en gran medida, de la disponibilidad y de la calidad de los recursos naturales. Y, por este motivo, la gestión ambiental y la gestión económica de la dehesa sólo podrán ser compatibles y complementarias cuando esté garantizada la rentabilidad económica de su actividad productiva. En el momento en que el balance contable comience a arrojar sistemáticamente pérdidas, los recursos ambientales de la dehesa, tanto si es por acción como si es por omisión de sus propietarios, correrán el mismo peligro que afrontaron cuando se inició el proceso de modernización de este tipo de explotaciones.

Es preciso asegurar, en consecuencia, que la sostenibilidad de la dehesa no está, ni mucho menos, garantizada. Actualmente, su rentabilidad económica depende en exceso de las primas comunitarias. Por tal motivo, cualquier modificación en la política de ayudas alterará los presupuestos económicos de la dehesa y exigirá la reconversión de sus esquemas productivos. Desde la perspectiva actual, la más que previ- 
sible reducción que experimentarán las primas al vacuno, ovino y caprino a lo largo del período 2007-2013 y su anunciada supresión a partir del 2014, implicarán la pérdida de rentabilidad económica de estas especies ganaderas y, en consecuencia, el probable abandono de su producción. Obviamente, esta circunstancia determinará la falta de disposición de los ganaderos para proceder a la conservación y mejora de los recursos genéticos autóctonos, hecho que, a su vez, puede poner al borde de la extinción a algunas razas locales. Por idéntico motivo, la atención y mejora de los pastos o el control del matorral pasarán a convertirse en actividades gravosas y carentes de interés empresarial, circunstancia ésta que inevitablemente conducirá a la degradación ambiental de la dehesa.

Obviamente, una vez iniciado este proceso, la pérdida de sostenibilidad de la dehesa no se limitaría a la vertiente ambiental, sino que se extendería también a la económica y social. Como ocurriera antaño, la pérdida de rentabilidad de la actividad ganadera repercutirá de modo especialmente negativo en las explotaciones más pequeñas o de menor capacidad financiera que, en muchos casos, se verán obligadas a cesar en su actividad y pasarán a integrarse en otras de mayor tamaño. Se desencadenará así una aceleración del proceso de acumulación de la tierra que, como en el pasado, irá en detrimento del desarrollo de estos espacios rurales, reavivará el flujo migratorio hacia las ciudades y conducirá hacia la despoblación de los municipios más pequeños. Para entonces, inexorablemente, la dehesa habrá dejado de encarnar un modelo de desarrollo sostenible.

Ciertamente, aún es posible adoptar medidas para rehuir tan pesimistas perspectivas de futuro. Algunas de ellas ya se han puesto en marcha en los últimos años, y pueden servir perfectamente como referentes de que aún no se han agotado las posibilidades para alcanzar mayores cotas de desarrollo en el marco de la dehesa. Si el cerdo ibérico ha conseguido superar crisis pasadas y situarse en niveles interesantes de rentabilidad sin recibir primas comunitarias, es necesario plantearse idénticas metas para las cabañas de vacuno y ovino.

La enfermedad de la Lengua Azul que viene afectando desde 2005 a las cabañas de vacuno y ovino extremeñas, andaluzas y castellanas, ha servido para poner de manifiesto algunas de las debilidades de la ganadería extensiva. La prohibición de vender terneros y corderos para vida ha provocado una retención del ganado en explotaciones habituadas a vender los animales al destete. La falta de pastos provocada por la prolongada ausencia de precipitaciones, la frecuente necesidad de comprar agua y el aumento del precio de los piensos, están gravando sobremanera la economía de la empresa ganadera. Si el engorde de los animales se efectuara en las propias explotaciones o en cebaderos gestionados en régimen de cooperativa, la 
situación hubiera sido bien diferente, ya que no existen restricciones para la salida del ganado con destino a sacrificio. En parte, pues, el futuro de la dehesa dependerá de la capacidad del empresariado para articular y gestionar de forma adecuada no sólo las fases de cría y recría de los animales, sino también las de cebo, sacrificio y comercialización. En su mayor parte, estas últimas se encuentran en manos de empresas especializadas, próximas a los grandes centros de consumo y desvinculadas de los ganaderos y de los medios rurales en los que éstos desarrollan su actividad.

Para las cabañas de vacuno y ovino, el camino hacia el futuro está marcado e inexcusablemente habrá de pasar por la creación de mercados específicos de calidad en los que el consumidor valore la naturaleza de unos productos únicos por los que, en consecuencia, estará dispuesto a pagar unos precios que garanticen la viabilidad económica de las explotaciones con independencia de las primas comunitarias. Y habrá que procurar además que, con la articulación entre las fases de producción, elaboración y comercialización, esta actividad genere en el medio rural todo el valor añadido que hoy sale fuera a través de empresas controladas y dirigidas desde los medios urbanos. Obviamente, para conseguir este objetivo es necesaria la creación de cebaderos en los que se proceda al engorde de los animales que actualmente salen de la dehesa tras el destete. Urge, igualmente, la construcción de mataderos dedicados al sacrificio de las reses, el despiece de las canales y la elaboración de la amplia gama de productos de charcutería que demandan los mercados actuales. Y, finalmente, es preciso impulsar la creación de denominaciones de origen que, aprovechando las exigencias de calidad y trazabilidad de los productos que requiere el moderno consumidor, garanticen la obtención de precios remuneradores para estas especies ganaderas. De forma simultánea, tales actuaciones propiciarán la generación de empleo en los medios rurales y evitarán un desequilibrio irreversible de los flujos migratorios.

Y en idéntico sentido habría que manifestarse respecto de algunos otros aprovechamientos agroforestales de la dehesa. El corcho de los alcornocales andaluces y extremeños continúa exportándose como materia prima hacia la industria catalana y portuguesa, sin generar en las regiones de origen otro valor añadido que el derivado de las operaciones de saca, raspado, cocido y enfardado que realizan los trabajadores de las zonas productoras. Asimismo, la leña que proporcionan las podas periódicas de encinas y alcornoques, cuya demanda para combustible y para la fabricación de carbón vegetal se sitúa en niveles importantes, tiene una repercusión muy escasa en la economía de las explotaciones ya que apenas alcanza para remunerar dicha labor cultural. Probablemente, el surgimiento de iniciativas empresariales de tipo cooperativista permitiría la adecuada valorización de estos productos y subproductos forestales que necesariamente deben constituir un complemento más para permitir la autonomía económica de la dehesa. 
Finalmente, el futuro de estas explotaciones habrá de pasar ineludiblemente por una adecuada gestión de los aprovechamientos etmergentes de los espacios adehesados. La caza comercial, el agroturismo o el disfrute de la naturaleza, aún no están ni suficiente ni convenientemente desarrollados, pero están llamados a constituir un complemento importante para la economía de la dehesa (Campos, 1993 y 1994). Sin embargo, no todas las explotaciones están en condiciones de desarrollar este tipo de actividades. El tamaño de las fincas, la calidad de los cortijos, la situación y la accesibilidad son, entre otras muchas, algunas de las condiciones que restringen sobremanera la proporción de dehesas con posibilidades reales de implementar este tipo de actuaciones. Y, aun en el mejor de los casos, sería absolutamente necesaria una intervención pública que diseñara diferentes modelos de ayuda para la conservación y restauración del patrimonio natural, pues su comercialización raramente repercute de forma directa en la economía de la empresa agraria. Las dehesas son espacios accesibles a través de los cauces públicos, servidumbres de paso, caminos de herradura o vías pecuarias y, en consecuencia, buena parte de sus recursos ambientales son perfectamente asequibles para todos.

Por otra parte, dicha intervención pública debe orientarse igualmente a favorecer el desarrollo rural de estas comarcas de dehesa que, hoy por hoy, pasan por ser, junto con las áreas de montaña, y pese a las innegables mejoras conseguidas, las que padecen una mayor incidencia del paro, las que tienen un saldo migratorio más elevado, las que presentan un mayor envejecimiento demográfico y, en suma, las que muestran mayor debilidad socio-económica (Barrientos, Pérez y Albergaria, 2005). Por el momento, el desacoplamiento total o parcial de algunas ayudas comunitarias aprobado en la reforma intermedia de la PAC no favorecerá la fijación poblacional que tanto necesita este territorio. Al contrario, la perspectiva de un pago único sólo condicionado a unas reglas de ecocondicionalidad servirá para reactivar la emigración rural hacia núcleos donde tanto los jóvenes como los mayores puedan ver satisfechas sus necesidades y sus aspiraciones sociales, económicas, culturales o acistenciales (Pérez y Barrientos, 2005).

En definitiva, pues, la conservación de los recursos ambientales de la dehesa sólo estará garantizada en la medida en que lo esté su rentabilidad económica y, hoy por hoy, ésta depende más de la financiación pública que del mercado. Por tal motivo, la reducción o supresión de las primas ganaderas en el horizonte del 2014 pueden marcar el final de la fase de bonanza que, desde finales de los años ochenta, vienen atravesando estas explotaciones y el territorio en el que se insertan. Si no se adoptan urgentemente algunas de las medidas anteriormente propuestas, la quiebra de la economía ganadera es inminente y, como en el pasado, tal situación puede conducir a actitudes y situaciones de perversas e irreversibles consecuencias ambientales, sociales y económicas. 


\section{Bibliografía}

Acosta, R. (2002): Los entramados de la diversidad. Antropología social de la debesa. Montijo. Excma. Diputación Provincial de Badajoz.

Antón, Ma . L. (2004): El organismo pagador de la Consejería de Agricultura y Medio Ambiente. Ayudas del FEOGA-Garantía pagadas en 2003. En Facultad de Ciencias Económicas y Empresariales y Escuela de Ingenierías Agrarias. Universidad de Extre-madura: La agricultura y la ganadería extremeñas. Informe 2003. Badajoz, Caja Badajoz, p. 107-116.

Barrientos, G.; Pérez, A. \& Albergaria, H. (2005): La población en la Raya extremeño-alentejana. Papeles de Economía Española. Economia de las CCAA, 25, p. 63-81.

Campos, P (1993): Valores comerciales y ambientales de las dehesas españolas. Agricultura y Sociedad, 66, p. 9-41.

Campos, P. (1994): Economía de los espacios naturales. El valor económico total de las dehesas ibéricas. Agricultura y Sociedad, 71, p. 243-256.

Díaz, A. \& Sánchez, J. (2004): Memoria económica 2003 de la agricultura extremeña. Macromagnitudes del sector agrario. En Facultad de Ciencias Económicas y Empresariales y Escuela de Ingenierías Agrarias. Universidad de Extremadura: La agricultura y la ganaderia extremeñas. Informe 2003. Badajoz. Caja Badajoz, p. $87-106$.

Elena, M. et al. (1982): Efectos de la producción de carbón vegetal en los encinares de Extremadura. Jornadas de Ecologia y Medio Ambiente. Villanueva de la Serena (Badajoz).

Escribano, M. A. Rodríguez, F. J. Mesías y Pulido, J. (2002): Niveles de cargas gana- deras en la dehesa extremeña. Archivos de Zootecnia. Vol. 51,195, p. 315-326.

Fernández, P. (1998): La debesa. Algunos aspectos para la regeneración del arbolado. Informaciones Técnicas 58/98.

Márquez, D. (1977): La geoeconomia forestal de Huelva y el dilema de sus eucaliptales. Sevilla. Publicaciones de la Universidad de Sevilla.

INIA (1972): Mapa provincial de suelos de Badajoz. Madrid. Ministerio de Agricultura.

Pérez, A. (1986): La ganadería extensiva extremeña ante la CEE. Perspectivas y problemática de los sectores ovino y caprino. IV Coloquio Ibérico de Geografía. Coimbra, p. 215-224.

Pérez, A. (1988): Cambios y problemática en la dehesa. Madrid. Servicio de Publicaciones de la Universidad de Extremadura.

Pérez, A. (1994): Extremadura: ¿Un espacio latifundista? VII Coloquio de Geografia Rural. Córdoba. Servicio de Publicaciones de la Universidad de Córdoba, p. 8489.

Pérez, A. (2003): La Política Agraria Común y la reconversión del campo extremeño. Norba. Revista de Historia, p. 685-699.

Pérez, A. \& Barrientos, G. (2005): Emigrantes, inmigrantes y retornados: Extremadura ante el siglo XXI. Badajoz. Excma. Diputación Provincial de Badajoz.

Puerto, A. (1997): La dehesa. Investigación y Ciencia, p. 66-73.

Rubio, J. M. (1999): Los paisajes de dehesa en función del manejo y la explotación. Extremadura y la trashumancia (siglos $X V I-X X)$. Mérida. Editora Regional de Extremadura, p. 149-161. 
Zavala, M. et al. (2004): Nuevas perspectivas en la conservación, restauración y gestión sostenible del bosque mediterráneo. En Valladares, F.: Ecologia del bosque medite- ráneo en un mundo cambiante. Madrid. Ministerio de Medio Ambiente, p. 509529. 